\title{
Effect of 12-week Swiss Ball Exercise Program on Physical Fitness and Balance Ability of Elderly Women
}

\author{
Byoung-Do SeO, MS, PT ${ }^{1)}$, Young-DeA Yun PhD, $\mathrm{PT}^{2)}$, \\ HEE-RA KIM PhD, PT ${ }^{3}$, SANG-Ho LEE PhD ${ }^{4}$ \\ 1) Department of Physical Therapy, College of Health, Kyungwoon University: 55 Induck-ri, \\ Sandong-myeon, Gumi Si, Gyeongsangbuk-Do, 730-739 Republic of Korea. TEL: +82 54-479-1374, \\ FAX: +82 54-479-1076, E-mail: oksbd@paran.com \\ ${ }^{2)}$ Department of Physical Therapy, Yonsei Semirae Hospital \\ 3) Department of Physical Therapy, BMC Oriental Hospital \\ 4) Research Institute of Sport Science, Kyungwoon University
}

\begin{abstract}
Purpose] This study examined the effect of a Swiss ball exercise program for elderly females on physical fitness and balance ability in order to offer basic data for the development of an exercise program to improve the quality of life and promote the health of elderly females. [Subjects] Sixty-five elderly women aged over 78 participated in this study. [Methods] The subjects were divided into two groups: an exercise group and a control group. The exercise group $(\mathrm{n}=38)$ performed a Swiss ball exercise program which consisted of 12 types of exercises required for balance and performance of functions twice a week for 12 weeks. Physical fitness (Sit-to-Stand, Arm Curl, Sit-and-Reach, Back Scratch) and balance ability (One-Legged Standing time, Timed Up \& Go) were evaluated. [Results] There was a significant increase in the physical fitness and balance ability of the exercise group. [Conclusion] The Swiss ball exercise program had a positive effect on physical fitness and balance ability of elderly women. We consider that the ball which is easy, safe and interesting to use will encourage the elderly's active participation in exercise.
\end{abstract}

Key words: Swiss ball exercise, Elderly women, Physical fitness, Balance ability

(This article was submitted Jul. 5, 2011, and was accepted Aug. 27, 2011)

\section{INTRODUCTION}

Today, average life expectancy due to the development of medical technology and standard of living has increased leading to an increase of elderly people. As a result, the elderly population aged 65 or over accounts for $10.3 \%$ of the total population in Korea. In 10 years from now, this percentage will be $14 \%$, and Korea will be an aging society. In 2026, the percentage of elderly will rise to $20 \%$, marking Korea as a super-aging society ${ }^{1)}$. As the increase of the elderly population is becoming a social issue, interest in the quality of elderly life has increased in many sections of society, and health problem of the elderly have been recognized as an important issue which needs to be covered at the level of government as well as family and the elderly themselves ${ }^{2,3)}$.

Physical fitness is defined as the ability to move the body efficiently, healthily and effectively in daily living, and it includes both fitness related to health and function. In general, aging works as the main cause in the decreases of physical fitness, leading to decrease of balance that in turn raises the risk of falls, early death of the elderly ${ }^{4-6)}$. Balance is the ability to keep the center of gravity on the base of support for static and dynamic movement. It is a complicated process involving sense, movement and the central nervous system, and their integrated coordination ${ }^{6}$. Balance is also the most essential factor for people to live daily life and perform purposeful activities such as walking ${ }^{2-5)}$. Reduced balance is caused by decreases of neuromuscular integration ability, adaptability, muscle strength and flexibility, and cognitive awareness ${ }^{2-5}$ ). Therefore, the improvement of physical fitness and balance ability of the elderly through proper physical activities and exercise programs should have a positive effect on improvement of quality of life enabling the elderly to manage their independent living.

Currently, various types of exercise programs are being used to increase the physical fitness and balance ability of the elderly. The most frequently used exercise methods are complicated training programs $(28.13 \%)$ that contain muscle strength, flexibility and balance training ${ }^{7)}$, and there is a lack of simple and effective exercise programs for the elderly to strengthen physical fitness. This study focused on a Swiss ball exercise program.

Swiss ball exercise is not only used for treatment purpose, but also by sports players to increase muscle 
strength and for neuropathy patients to increase balance. It is very easy, safe and interesting, so men and women of all ages can do it without the need for large spaces or expense $^{8,9)}$. Also, core muscles not usually used during common exercises are recruited in order to keep stability due to the instability of ball itself ${ }^{9}$ ). Thus, Swiss ball exercise requires more sense of balance and its positive effects are reinforcement of muscle strength and endurance, increase of flexibility, increase of joint stability and coordination, and enhancement of proprioception ${ }^{10,11)}$.

Therefore, the aim of this study was to examine the effect of Swiss ball exercise program for elderly females, especially its effect on physical fitness and balance ability in order to offer basic data for the development of an exercise program for improving the quality of life and promote the health of elderly females living in a farm village.

\section{SUBJECTS AND METODS}

Sixty-five elderly women aged over 78 participated in this study from July 8 to September 21, 2010 for 12 weeks. The subjects who had no special exercise experience in the previous 6 months, no serious impairment of the visual or vestibular organs and normal cognitive function (MMSE-K: 24 point or more, GDS: 14 point or below) were selected by a survey ${ }^{12,13)}$. The subjects were divided into two groups: an exercise group and a control group. The exercise group $(n=38)$ performed Swiss ball exercise twice a week for 12 weeks. The control group $(n=40)$ performed their daily activities only. The subjects were told about the general purpose, method and details of the study and signed a consent form before participation.

Physical fitness and balance were evaluated. Physical fitness had two items: muscle strength and flexibility. To evaluate muscle strength, the Sit-to-Stand test was performed for the lower limbs and the Arm Curl test for the upper limbs. To evaluate flexibility, the Sit-and-Reach test and Back Scratch test were performed. To evaluate balance, One-Legged Standing time and the Timed Up \& Go were measured.

The sit-to-Stand test (women: $\mathrm{r}=0.71)^{14)}$ evaluate muscle strength of the lower limbs. Subjects sit in a chair with their arms folded in front of the chest, and stand up and sit down repeatedly for 30 seconds. The number of times (unit: sec) is recorded. The Arm Curl test (women: $r=0.79)^{15}$ ) evaluates muscle strength of the upper limbs. Subjects sit in a chair with their feet touching the floor and perform bicep curls while holding a $1.8 \mathrm{~kg}$ weight with the palm upward for 30 seconds. The number of times (unit: Num) is recorded. The Sit-and-Reach test $\left.(\mathrm{r}=0.61 \text { to } 0.89)^{16}\right)$ evaluates flexibility of the lower limbs. Subjects sit in a chair and stretch both legs. Then they bend forward to touch their toes or put their hands beyond their toes. The distance between fingers and toes is measured with negative values being given when fingers do not reach the toes (unit: $\mathrm{cm}$ ). The Back Scratch test ${ }^{17)}$ evaluates the flexibility of the upper body. In the standing position, subjects place one hand behind the head and back over the shoulder, and reach as far as possible down the middle of the back, with their palm touching their body and the fingers directed downwards while placing the other arm behind the back, palm facing outward and fingers upward and reaching up as far as possible attempting to touch or overlap the middle fingers of both hands. The distance between the finger tips is measured with negative values being given when the fingers do not touch (unit: $\mathrm{cm}$ ).

One-Legged Standing time evaluates static balance ${ }^{18)}$. In the standing position, subjects spread out both arms horizontally and bend one leg to $90^{\circ}$ with their eyes closed. The length of time for which subjects can maintain this posture is measured. This test was performed twice and the maximum value was recorded (unit: sec). Functional mobility was assessed using the Timed Up \& Go test. Several studies have reported its high test-retest reliability $(\mathrm{ICC}=0.97)^{19)}$ and excellent intra- and inter-reliability $(\mathrm{ICC}=0.99)^{20)}$. A distance of $3 \mathrm{~m}$ was determined and adhesive tape was fixed to the floor to mark it as a reference line. The test started and ended with the subject seated in an armless chair with keeping their knees flexed at $90^{\circ}$ and their arms at their sides for balance. Subjects were asked not to use their hands when standing up and sitting down. The time taken to complete the task was measured. The test was performed twice and the maximum value was recorded (unit: sec).

The Swiss ball exercise program consisted of 12 types of exercises required for balance and performance of functions twice a week for 12 weeks: warm up (10 $\mathrm{min})$, exercise (30 min) and cooling-down exercise (10 min) (Table 1). The ball used in this program was $55 \mathrm{~cm}$ in diameter, and it was selected with consideration of the height of the subjects. For warm up and cooling-down exercises, stretching was performed to increase flexibility of the joints and a break time of three minutes was inserted between each set in consideration of the physical strength of the subjects. Each exercise was performed in three steps from the easy to difficult level: ball exercise in the lying-down position (Table 1, 1-7), ball exercises sitting on the ball (Table 1, $8-10)$, and ball exercises using the wall (Table 1, 11, 12). The program lasted for 12 weeks and the number of repetitions and sets were gradually increased by session. The intensity of exercise was the level that the subjects felt was 'a little difficult' based on the Borg Scale. If the subjects experienced difficulty during the exercise due to feeling lightheaded or dizzy, they stopped the exercise and took a rest.

SPSS (SPSS 12.0 KO for Windows, SPSS Inc, Chicago, USA) was used to analyze the collected data. Two-way repeated measures ANOVA (group $\times$ time) and the paired t-test were performed to compare measured items pre and post the exercise within each group. The independent t-test was performed for comparisons between groups. Statistical significance was accepted at values of $\mathrm{p}<0.05$.

\section{RESULT}

The general characteristics of subjects are shown in Table 2. There were no significant differences between the two groups except for GDS, but a score below 14 is in the normal range. In the two-way repeated measures ANOVA (group $\times$ time), the results of changes in physical fitness 
Table 1. Swiss ball exercise program of 12 weeks

\begin{tabular}{lcccc}
\hline & $\begin{array}{c}1-3 \\
\text { Weeks }\end{array}$ & $\begin{array}{c}4-6 \\
\text { Weeks }\end{array}$ & $\begin{array}{c}7-9 \\
\text { Weeks }\end{array}$ & $\begin{array}{c}10-12 \\
\text { Weeks }\end{array}$ \\
\hline 1. Bridging on the ball & $10 \times 3^{*}$ & $10 \times 4$ & $5 \times 4$ & $5 \times 4$ \\
2. Hip adduction & $3 \times 5$ & $5 \times 5$ & $3 \times 5$ & $3 \times 5$ \\
3. Leg raise holding the ball between the feet & $3 \times 5$ & $5 \times 5$ & $3 \times 5$ & $3 \times 5$ \\
4. Knee flexion & $3 \times 5$ & $5 \times 5$ & $3 \times 5$ & $3 \times 5$ \\
5. Sit up on the ball: trunk flexion & $3 \times 5$ & $5 \times 5$ & $3 \times 5$ & $4 \times 5$ \\
6. Back extension on the ball: trunk extension & & $3 \times 3$ & $3 \times 4$ & $4 \times 4$ \\
7. Bounce on the ball & & $3 \times 3$ & $3 \times 4$ & $4 \times 4$ \\
8. Pelvic rotation on the ball & & $3 \times 3$ & $3 \times 4$ & $4 \times 4$ \\
9. Knee extension on the ball & & $3 \times 3$ & $3 \times 4$ & $4 \times 4$ \\
10. Pelvic ant./ post./ lat. tilt on the ball & & & $2 \times 3$ & $3 \times 3$ \\
11. Side bridging: trunk lateral bending & & & $2 \times 3$ & $3 \times 3$ \\
12. Ball push facing the wall & & & & $2 \times 3$ \\
*Repeat $\times$ Set & & & & $3 \times 3$ \\
\hline
\end{tabular}

Table 2. General characteristics of subjects

\begin{tabular}{lcc}
\hline & Exercise group $(\mathrm{n}=38)$ & Control group $(\mathrm{n}=40)$ \\
\hline Age (years) & $71.65 \pm 8.06$ & $72.35 \pm 8.42$ \\
Height $(\mathrm{cm})$ & $160.46 \pm 4.06$ & $158.27 \pm 6.51$ \\
Weight $(\mathrm{kg})$ & $56.72 \pm 6.38$ & $57.78 \pm 6.21$ \\
Blood pressure & & \\
Systolic (mmHg) & $128.52 \pm 12.03$ & $132.22 \pm 9.91$ \\
Diastolic (mmHg) & $85.79 \pm 6.25$ & $87.45 \pm 6.52$ \\
BMI & $22.06 \pm 2.61$ & $22.75 \pm 2.92$ \\
MMSE-K (score) & $26.05 \pm 1.41$ & $26.00 \pm 1.39$ \\
GDS (score) & $11.13 \pm 2.36$ & $9.95 \pm 2.43^{*}$ \\
\hline
\end{tabular}

Mean \pm SD. ${ }^{*} \mathrm{p}<0.05$. BMI: Body Mass Index. MMSE-K: Mini-Mental State Examination-Korean version. GDS: Geriatric Depression Screening Scale - Korean version.
Table 3. Change in physical fitness pre and post Swiss ball exercise

\begin{tabular}{llcl}
\hline Variable & Group & Pre-exercise & Post-exercise \\
\hline $\begin{array}{l}\text { Sit-to-Stand } \\
\text { (num) }\end{array}$ & Exercise group & $13.47 \pm 3.25$ & $14.63 \pm 3.58^{*}$ \\
\hline Arm Curl & Control group & $14.13 \pm 3.49$ & $13.93 \pm 3.43$ \\
(num) & Exercise group & $17.66 \pm 2.75$ & $18.11 \pm 2.99^{* *}$ \\
\hline Sit-and-Reach & Exercise group & $-2.46 \pm 1.49$ & $-1.88 \pm 1.53^{* * *}$ \\
(cm) & Control group & $-2.65 \pm 1.66$ & $-2.69 \pm 1.60$ \\
\hline Back Scratch & Exercise group & $0.36 \pm 1.38$ & $0.85 \pm 1.26^{*}$ \\
(cm) & Control group & $0.29 \pm 1.39$ & $0.36 \pm 1.24$ \\
\hline
\end{tabular}

Mean \pm SD. ${ }^{*} \mathrm{p}<0.05,{ }^{* *} \mathrm{p}<0.01,{ }^{* * *} \mathrm{p}<0.001$, significant difference between groups.

Table 4. Change in balance ability pre and post Swiss ball exercise

\begin{tabular}{cccc}
\hline Variable & Group & Pre-exercise & Post-exercise \\
\hline \multirow{2}{*}{ One Legged Stand (sec) } & Exercise group & $7.84 \pm 2.48$ & $8.65 \pm 1.98^{* *}$ \\
& Control group & $8.87 \pm 1.76$ & $8.81 \pm 1.69$ \\
\hline \multirow{2}{*}{ Timed Up \& Go $(\mathrm{sec})$} & Exercise group & $17.43 \pm 3.75$ & $15.88 \pm 3.72^{* * *}$ \\
& Control group & $18.5 \pm 3.79$ & $18.36 \pm 3.75$ \\
\hline \multirow{2}{*}{ Mean \pm SD. ${ }^{*} \mathrm{p}<0.05,{ }^{* *} \mathrm{p}<0.01,{ }^{* * *} \mathrm{p}<0.001$, significant difference between groups. }
\end{tabular}

(muscle strength and flexibility of the upper and lower body) of the elderly subjects pre and post Swiss ball exercise are shown in Table 3. Sit-to-Stand counts showed significant increase between pre and post exercise $(p=0.029)$ and between groups $(p=0.024)$. Arm Curl counts showed significant increases between pre and post exercise $(p=0.027)$ and between groups $(p=0.008)$. Sit-and-Reach distances showed significant improvements between pre and post exercise $(\mathrm{p}=0.001)$ and between groups $(\mathrm{p}=0.001)$. Back Scratch distances showed significant increases between pre and post exercise $(p=0.000)$ and between groups $(p=0.034)$. The results of change in balance, pre and post Swiss ball exercise are shown in Table 4. One-Legged Standing time showed significant increase between pre and post exercise $(p=0.012)$ and between groups $(p=0.006)$. Timed Up \& Go times showed significant decreases between pre and post exercise $(p=0.000)$ and between groups $(\mathrm{p}=0.000)$.

\section{DISCUSSION}

Weakening of physical fitness and reduction of balance ability due to aging increases the risk of falls, which may not only raises medical expenses but also lower the quality of life in old age. To prevent this, the importance of exercise programs for the elderly is being highlighted. Swiss ball exercise offers both stable and dynamic mobility which are useful for strengthening muscles and balance ability, respectively. These exercises are not boring due to the various motions of the ball and absorbs shock more than other muscle strength and balance exercises, so it is appropriate for elderly women ${ }^{8-11)}$. This study was designed to 
analyze the effect of a Swiss ball exercise program twice a week for 12 weeks on physical fitness and balance of elderly women aged 65 or over.

Sung et al. $(2003)^{21)}$ found a significant decrease in Timed Up \& Go times as well as increases in muscle endurance and flexibility of the upper and lower body (left) after a 12 week dance and ball exercise program. Also, Jang et al. $(2007)^{22)}$ found a significant increase in muscle endurance $(9.88 \pm 5.73$ to $13.81 \pm 5.42)$, flexibility $(17.28 \pm$ 4.86 to $20.18 \pm 5.34)$ and grip strength $(24.81 \pm 4.01$ to $26.96 \pm 4.01)$ after a combined exercise with a ball and band, which improved the physical strength of middle aged women. Campbell et al. (1997) ${ }^{23)}$ reported that a significant improvement was found in balance of elderly women who had muscle and balance training, three times a week for 6 months. These results were similar to those observed in the current study and we consider that regular exercise can change muscle strength and balance based on our present results and those of these previous studies. An unstable ball surface requires appropriate strength and balance to keep a posture ${ }^{8,9}$. Also, an increase in the number of muscle fibers created for the performance of the exercise is considered to lead an increase in muscle strength, thereby improving muscle endurance of the upper and lower body ${ }^{10,11)}$. This muscle strength is required for performing activities of daily living such as walking, climbing the stairs and carrying things, which are considered necessary for independent daily living ${ }^{23-25)}$. Flexibility of the upper and lower body was also increased by stretching in the warm-up, cooling-down and Swiss ball exercises, leading to relaxation of joint and muscle. This improvement in flexibility expands the range of motion, leading to prevention and rehabilitation of musculoskeletal injury ${ }^{22-24)}$. The Swiss ball exercise program for the elderly was effective at improving the physical fitness of the elderly in muscle endurance, flexibility, grip strength and walking.

On the relationship between elderly exercise and balance, Lee $(2008)^{26)}$ reported that both static balance $(4.96 \pm 0.98$ to $6.90 \pm 2.14)$ and dynamic balance $(11.32 \pm$ 6.93 to $15.68 \pm 5.69)$ were significantly increased in the elderly after a 12 week gym ball exercise. Chae $(2006)^{27)}$ also reported that both static balance $(4.96 \pm 0.98$ to $6.90 \pm$ $2.14)$ and dynamic balance $(11.32 \pm 6.93$ to $15.68 \pm 5.69)$ were significantly improved in middle aged women by an 8 week gym ball exercise, five times a week, that the result is corresponding to that of this study. Han et al. (2008) ${ }^{28)}$ reported that a ball exercise group and a band exercise group showed improvements in both static balance and dynamic balance after an 8 week program. Especially, the ball exercise $(7.37 \pm 1.43$ to $15.5 \pm 0.90)$ was more effective than the band exercise $(9.25 \pm 3.54$ to $13.75 \pm 2.56)$ for static balance improvement. Topp et al. (1993) ${ }^{29)}$ found improvements in the balance of the elderly after 12 weeks of rhythmic balance exercise. These results were similar to those observed in the current study.

The instability of the ball itself is considered to quickly activate small postural muscles that are not frequently used as well as stimulate proprioception and the somatosensory system for keeping balance, contributing to improvement of static and dynamic balance ability ${ }^{26-29)}$.This improvement of balance ability is considered to reduce shaking posture and the risk of falls and to have the elderly spend more positive and active living ${ }^{2,4}$. We showed that the Swiss ball exercise program had a positive effect on balance ability as well as physical fitness of elderly women and is an effective program for the prevention of falls and the promotion of health. Furthermore, many studies have reported significant effects after exercise periods of 8 weeks to 12 weeks or longer. In this study, the exercise, program twice a week for 12 weeks, resulted in significant improvements. Taken together, these results demonstrate that ball exercise for 8 weeks or longer improves the physical fitness and balance ability of elderly women. However, this study involved only a small number of subjects and follow-up studies are necessary to identify the significance of the physical fitness and balance ability improvements.

\section{REFERENCES}

1) 2008 year, aged population statistics. Korean National Statistical Office, 2009.

2) Kim MH: A study on the factors which influence the successful aging among Korean elderly groups. Journal of the Korean Data Analysis Society, 2010, 12: 697-716.

3) Paik JE: The relationships of life support and death anxiety for elderly. Journal of the Korean Data Analysis Society, 2010, 12: 3117-3136.

4) Brown M, Sinacore DR, Host HH: The relationship of strength to function in the older adult. J Gerontol, 1995, 50: 55-59.

5) Lee AS, Yoon CK: Risk factor of falls in hospital for the elderly. Journal of the Korean Data Analysis Society, 2010, 12: 2511-2524.

6) Tinetti ME, Williams CS: Falls, injuries due to falls, and the risk of admission to a nursing home. N Engl J Med, 1997, 337: 1279-1284.

7) Jeoung BJ: A review of exercise program for fall prevention in the elderly. The Journal of Korean Society of Aerobic Exercise, 2008, 12: 1-9

8) Detz J: Ultimate Core Ball Workout: Strengthening and Sculpting Exercises with Over 200 Step-by-Step Photos. Berkley: Ulysses Press, 2005.

9) Milligan J: Health Series: Swiss Ball for Total Fitness. United State: Main Street, 2005.

10) Kim MS: Effects of Swiss ball exercise on moire topography and detraining in high school female students with scoliosis. Journal of Korean Physical Education Association for Women, 2010, 21: 29-39.

11) Kim YW, Kim MS: The effects of 12 weeks yoga, elastic band exercise and Swiss ball exercise program on physical function improvement for breast cancer survivor. Journal of Sport and Leisure Studies, 2009, 35: 1051-1060.

12) Park JH, Kwon YC: Standardization of Korean version of the Mini-Mental State Examination (MMSE-K) for use in the elderly, part II: Diagnostic validity. Journal of the Korean Neuropsychiatric Association, 1989, 23: 508-513.

13) Jo MJ, Bae JN, Seo KH, et al.: Validation of Geriatric Depression Scale, Korean version (GDS) in the assessment of DSM-III-R Major Dep. Journal of the Korean Neuropshychiatric Association, 1999, 38: 48-63.

14) Jokne CJ, Rikli RE, Beam WC. A30-s chair-stand test as a measure of lower body strength in community-residing older adults. Res Q Exerc Sport, 1999, 70: $113-119$.

15) Roberta E, Rikli C, Jessie Jones: Senior fitness test manual. USA: Human Kinetics Publishers, 2005.

16) Jackson AW, Baker AA: The relationship of the sit and reach test to criterion measures of hamstring and back flexibility in young females. Res Q Exerc Sport, 1986, 57: 183-186.

17) Collins K, Rooney BL, Smalley KJ, et al: Functional fitness, disease and 
independence in community-dwelling older adults in western Wisconsin. WMJ, 2004, 103: 42-48

18) Vellas BJ, Wayne SJ, Romero L, et al: One-leg standing balance is an important predictor of injurious falls in older persons. J Am Geriatr Soc, 1997, 45: 735-738.

19) Carter ND, Khan KM, Petit MA, et al.: Results of a 10 week community based strength and balance training programme to reduce fall risk factors: A randomised controlled trial in 65-75 year old women with osteoporosis. $\mathrm{Br}$ J Sports Med, 2001, 35: 348-351.

20) Steffen TM, Hacker TA, Mollinger L: Age and gender related test performance in community-dwelling elderly people: Six-minute walk test, Berg Balance Scale, Timed Up \& Go Test and Gait Speeds. Phys Ther, 2002, 82: 128-137.

21) Sung HR, Yang JH, Kim MS: Effects of dance and Swiss ball exercise program on functional fitness in the older adult women. The Journal of Korean Society of Growth and Development, 2003, 11: 89-96.

22) Jang JH, Hur S, Hong KY: Effects of Swiss ball-elastic band exercise for 1 year on body composition, physical fitness and bone mineral density and correlations of psychosocial factors in middle-aged women. The Korean Journal of Physical Education, 2007, 46: 493-501.
23) Campbell AJ, Robertson MC, Gardner MM, et al.: Randomised controlled trial of a general practice programme of home based exercise to prevent falls in elderly women. BMJ, 1997, 25: 1065-1069.

24) McCartney N, McKelvie RS, Martin J, et al.: Weight training induced attenuation of the circulatory response of older males to weight lifting. J Appl Physiol, 1993,74: 1056-1060.

25) Thomas M, Muller T, Busse MW: Quantification of tension in thera-band and can do tubing at different stains and starting lengths. J Sports Med Phys Fitness, 2005, 45: 188-198.

26) Lee SC: Effect of 12 week Swiss ball exercise physical fitness and balance in elderly. Dissertation of Graduate School, Kook-Min University, 2008.

27) Chae JH: Effect of Swiss-ball exercise for middle-aged woman's body composition and physical fitness. Dissertation of Graduate School, Keimyun University, 2006.

28) Han SW, Lee JW, Kim SH: Effects of the Swiss ball and thera-band exercise on the balance of the elderly. Journal of Sport and Leisure Studies, 2008, 34: 945-953.

29) Topp R, Mikesky A, Wigglesworth J, et al.: The effect of a 12-week dynamic resistance strength training program on gait velocity and balance of older adults, Gerontologist, 1999, 33: 501-506. 